\title{
Uzaktan Algılama ve CBS Teknikleri ile Peyzaj Çeşitliliği ve Karbon Depolama Potansiyeli Arasındaki iliş̧kinin İncelenmesi
}

\section{Derya GüLÇiN ${ }^{* 1}$ [D}

\author{
${ }^{1}$ Aydın Adnan Menderes Üniversitesi, Ziraat Fakültesi, Peyzaj Mimarlığı Bölümü, Çakmar, AYDıN
}

Öz: Antropojenik faaliyetler kaynakıı Arazi Kullanımı/Arazi Örtüsü (AK/AO) değişimi, önemli miktarda toprak tahribatı ve arazi kaybına neden olmuştur. Bu nedenle, özellikle son on yılda Akdeniz'de karbon tutulumu azalmıştır. Arazi verisinin eksik olduğu alanlarda karbon depolanmasını tahmin etmek için deneysel varsayımlara dayanan küresel değerler, uzaktan algılama teknikleri ile yerel karbon stoklarının basitleştirilmiş tahminlerinde kullanılabilir. Bu çalışmanın amacı, peyzaj çeşitliliği ve karbon depolama potansiyeli arasındaki ilişkinin uzaktan algılama ve CBS aracılı̆ı̀la incelenmesidir. Manisa il sınırı bütününden oluşan peyzajda yürütülen bu çalışmada, güncel arazi kullanımı/arazi örtüsü verisi kullanılarak, farklı mesafelerdeki örneklik alanlar için peyzaj çeşitliliği metriklerinden Shannon çeşitlilik indeksi (SHDI), yama yoğunluğu (PRD) ve Simpson eşitlik indeksi (SIEI) hesaplanmıştır. Çeşitlilik değerleri ile yer üstü karbon tutumu değerleri korelasyon analizi ile değerlendirilmiştir. Sonuç olarak, kullanılan tüm peyzaj çeşitlilik metrikleri peyzaj çeşitliliği ve karbon depolama potansiyeli arasındaki ilişkiyi 3000 m'de en iyi düzeyde açıklamıştır. SHDI'nın bu ilişkiyi diğer metriklere göre daha iyi açıkladığı görülmüştür $(p<0.05)$. Ancak ilişkinin düzeyi ortadır ve yönü pozitiftir. Bundan sonraki çalışmalarda, AK/AO verisini kullanılarak karbon depolama potansiyelinin hızl, pratik ve daha yüksek güvenilirlik seviyesinde ölçülmesini sağlayacak yeni metrikler üretilebilir. Böylece, AK/AO değişimlerine bağlı olarak arazideki karbon depolama potansiyeli değişimi de pratik olarak izlenebilir.

Anahtar kelimeler: Shannon çeşitlilik indeksi, karbon tutma, peyzaj metrikleri, peyzaj ekolojisi, peyzaj planlama

Exploration of the Relationship Between Landscape Diversity and Carbon Storage Potential Using Remote Sensing and GIS

Abstract: Human-induced Land Cover / Land Use (LCLU) changes have caused land degradation in the last decade and have led to an intense reduction of carbon especially in the Mediterranean basin. Remote sensing based metrics based on experimental assumptions to predict carbon storage can be used in simplified estimates of local carbon stocks where field data is missing. The aim of this study is to examine the relationship between landscape diversity and carbon storage through remote sensing and GIS. Conducted in Manisa, this study used LCLU data dated 2018, three landscape diversity metrics -Shannon's diversity index (SHDI), patch richness density (PRD), and Simpson's evenness index (SIEI) were calculated for sample areas at different distances. Diversity values and aboveground carbon storage values were evaluated by correlation analysis. As a result, all landscape diversity metrics explained the relationship between landscape diversity and carbon storage at medium level for $3000 \mathrm{~m}$. This study suggests that SHDI explains this relationship better than other metrics $(p$ <0.05). Future studies can generate new metrics that will allow cost effective and practical measurement of potential carbon storage using LCLU data. Thus, changes in carbon storage can also be practically monitored.

Keywords: Shannon's diversity index, carbon capture, landscape metrics, landscape ecology, landscape planning

\section{GiRiş}

Arazi Kullanımı/Arazi Örtüsü (AK/AO) değişikliğinin etkileri, küresel çevresel değişimin incelenmesinde yaygın olarak göz önünde bulundurulmaktadır (Hu ve ark., 2019; Verburg ve ark., 2019; Liu ve ark., 2020). Geçtiğimiz 50 yıl boyunca ekosistemler, özellikle toprakların binlerce yıldır işlendiği Akdeniz'de tarihin herhangi bir döneminde olduğundan daha hızlı ve kapsamlı bir şekilde değişmiştir. Insan kaynaklı $A K / A O$, değişimi toprak bozulmasına ve arazi kaybına neden olmuş ve dünya çapında karbon depolamasında, son on yılda Akdeniz'de daha yoğun bir karbon azalmasına yol açmıştır (Muñoz-Rojas ve ark., 2015; Brunori ve ark., 2017). Özellikle son on yılda, AK/AO üzerindeki değişiklikler, ormansızlaşma ve tarımsal yoğunlaşma, $\mathrm{CO}_{2}$ emisyonları yoluyla küresel ısınma sürecini önemli ölçüde etkilemiştir (Chen ve ark., 2020). Yakıt tüketiminden sonra AK/AO üzerindeki değişiklikler, $\mathrm{CO}_{2}$ emisyonlarının ikinci ana nedeni olarak kabul edilmiştir (Houghton ve Nassikas, 2017; Yu ve ark., 2019).

Karbon stoklarının miktarının ortaya konmasındaki en büyük belirsizliklerden birisi, bitkilerin farklı yetişme koşullarına bağlı olarak değişen dendrometrik özelliklerini kullanarak biyokütlelerinin tahmin edilmesinde standart modellerin olmamasıdır (Chave ve ark., 2005). Bu nedenle, küresel iklim değişikliğini azaltmaya yönelik yapılan projeleri uygulamak için, sistemli olarak ağaçların ve çalıların bitki biyokütlesinin önemli bir bölümünü örnekleyecek ölçüde farklı ekosistemlerde depolanan karbon hakkında yer temelli bilgilerin toplanması çok önemlidir (Patenaude ve ark., 2004; Ni-Meister ve ark., 2010).

*Sorumlu Yazar: derya.yazgi@adu.edu.tr

Geliş Tarihi: 5 Kasım 2020

Kabul Tarihi: 21 Nisan 2021 
Çevresel izleme ve değerlendirme, antropojenik sera gazı emisyonu miktarının tahmin edilmesine katkıda bulunmaktadır (Golkar ve Shirvani, 2020). Uzaktan algılama, sınırlı veri kullanılabilirliği veya erişilebilirliği olan geniş alanlarda arazi örtüsündeki değişiklikleri gözlemlemek için etkili yöntemler sağlar (Dewan ve Yamaguchi, 2009; Chowdhury ve ark., 2020). Arazi verisinin eksik olduğu alanlarda, karbon depolanmasını tahmin etmek için deneysel varsayımlara dayanan küresel değerler, yerel karbon stoklarının basitleştirilmiş tahminlerinde kullanılabilir (Myeong ve ark., 2006).

Peyzaj planlama kapsamında, peyzaj çeşitliliği temelli çalışmaların ana değerlendirme ölçütü biyolojik çeşitliliktir. Dolayısıyla, peyzaj çeşitliliği ve biyolojik çeşitlilik arasında anlamlı ve güçlü bir ilişki vardır (Singh ve ark., 2018). Arazi kullanım şeklinin değişmesi ve arazi örtüsünün tahrip olması sonucunda oluşan biyolojik çeşitlilik kaybı, arazi ve atmosfer arasındaki $\mathrm{CO}_{2}$ değişimlerinde önemli bir değişikliğe neden olabilir (Hooper ve ark., 2012). Bu değişiklik, "biyolojik çeşitlilik kaybı ve varyasyonu, karbon depolamanın temel ekosistem süreçlerini değiştirecek mi?" sorusunu gündeme getirmiştir. Bu soruyu ele almak için, geçtiğimiz 30 yılda, biyolojik çeşitlilik ve ekosistem işlevleri arasındaki ilişkilerin belirlenmesine giderek daha fazla önem verilmiştir (Strassburg ve ark., 2010; Sabatini ve ark., 2019). Biyoçeşitlilik kaybı nispeten çalışılmış olsa da, peyzaj çeşitliliği ve potansiyel ekosistem işlevleri arasındaki ilişkinin nicel değerlendirmeleri, özellikle peyzaj çeşitliliği ile karbon depolama potansiyeli arasındaki ilişki yeterince ele alınmamıştır (Harpole ve ark., 2016).

Karasal ekosistemlerde, biyoçeşitlilik yer üstü biyokütlenin hem büyüklüğünü hem de değişkenliğini etkiler (Cardinale ve ark., 2013). Yer üstü biyokütle, küresel karbon bütçesini dengelemede önemli bir rol oynayan ekosistemin karbon depolama potansiyelini önemli ölçüde belirleyebilir (Davies ve ark., 2011). Biyoçeşitlilik-karbon tutma ilişkisine ilişkin güncel teoriler, biyolojik çeşitliliği, tamamlayıcılık etkisi veya kütle oranı etkisi yoluyla karbon depolamayı etkileyen önemli bir faktör olarak tanımlamaktadır (Sintayehu ve ark., 2020). Niş tamamlayıcılık hipotezi, türlerin farklı özelliklerinin daha yüksek fonksiyonel özelliklere sahip olduğunu ve bu nedenle kaynakları daha iyi kullanmaya yardımcı olabileceğini belirtirken, kütle oranı hipotezi, çeşitliliğin seçim etkileri yoluyla üretkenliği artırabileceğini belirtmektedir (Sande ve ark., 2017; Yuan ve ark., 2018). Biyoçeşitlilik değişimi göz önünde bulundurularak peyzaj çeşitliliğinin karbon depolamayı nası etkilediğinin anlaşıması, özellikle hassas ekosistemler için doğrudan koruma, koruma ve restorasyon planlarına yardımcı olacaktır. Özellikle orman alanlarında yer üstü karbon stoklarını korumak, küresel iklim değişikliğini azaltmak için 90 çok önemlidir ve eş zamanlı olarak peyzaj çeşitliliğini de koruyacağı varsayılmaktadır (Jantz ve ark., 2014; Perre ve ark., 2018).

Peyzaj modelleri hakkında zenginleştirilmiş bilgileri temsil eden peyzaj metrikleri, peyzaj yapısının bileşimini ve mekânsal arazi kullanım tahsisinin niteliklerini yansıtan nicel ölçümlerdir (Lausch ve Herzog, 2002; Uuemaa ve ark., 2009; McGarigal, 2014; Sütünç ve Çorbacı, 2020). Peyzaj metrikleri, peyzaj desenlerini incelemek için yararlıdır ve özelliklerin ve peyzaj kompozisyonunun mekânsal dağılımının nicel analizinde yardımcı olur (Botequilha Leitão ve Ahern, 2002; Cushman ve ark., 2008). Ayrıca, bu metrikler peyzaj yapıları ve ekolojik süreçler arasındaki ilişkilerin belirlenmesini sağlar (Lausch ve ark., 2015). Ekolojik işlevlerin analiz edilmesi için peyzaj metriklerinin kapsamlı kullanılması, peyzaj analizinin geçerliliğini artırabilir ve benzer peyzajlarda veri ekstrapolasyonuna izin verebilir (Frank ve ark., 2012). Aksine, peyzaj ölçümlerinin uygunsuz kullanımı, mekânsal modeller ve süreçler arasındaki ilişkilerin değerlendirilmesini engelleyebilir (Li ve Wu, 2004). Peyzaj metrikleri, ekolojik işlevlerle yakından ilişkiliyse ve önemli mekânsal dağııım bilgilerini yansıtıyorsa, ekolojik süreçler ve temel peyzaj yapıları arasındaki bağlantıyı gösterebilir.

Bu çalışmada, Manisa'da peyzaj çeşitliliği ve karbon tutma arasındaki ilişkinin incelenmesi amaçlanmıştır. Bu kapsamda, 2018 yılına ait AK/AO verisi kullanılarak, farklı mesafelerdeki örneklik alanlarda peyzaj çeşitliliği metriklerinden Shannon çeşitlilik indeksi (SHDI), yama yoğunluğu (PRD) ve Simpson eşitlik indeksi (SIEI) hesaplanmıştır. Çeşitlilik değerleri ile toprak üstü karbon tutumu değerleri, korelasyon analizi ile değerlendirilmiştir. Sonuç olarak, peyzaj çeşitliliği ve karbon tutma arasındaki ilişki açıklanmıştır. Gelecek çalışmaların bu ilişkiyi kullanması ve AK/AO verilerini kullanarak doğrudan karbon depolama potansiyelini tahmin etmesi tartışılmıştır.

\section{MATERYAL VE YÖNTEM}

Bu çalışma, Anadolu Yarımadası'nın batısındaki Manisa il sınırında yürütülmüştür. Araştırma alanı, $27^{\circ} 08^{\prime}$ ve $29^{\circ} 05^{\prime}$ doğu boylamları ile $38^{\circ} 04^{\prime}$ ve $39^{\circ} 58^{\prime}$ kuzey enlemleri arasında yer almaktadır. illde toplam 17 ilçe (Ahmetli, Akhisar, Alaşehir, Demirci, Gölmarmara, Gördes, Kırkağaç, Köprübaşı, Kula, Salihli, Sarıgöl, Saruhanlı, Selendi, Soma, Şehzadeler, Turgutlu, Yunusemre) bulunmaktadır (Şekil 1). Türkiye istatistik Kurumu 2019 yılı verilerine göre nüfusu 1.440.611 olan ilin \%82'si Gediz Havzası sınırındadır ve yüzölçümü $13.339 \mathrm{~km}^{2}$ dir. Ege bölgesinin önemli doğal göllerinden birisi olan Marmara Gölü il sınırları içerisindedir. Çalışma alanının batısında ve Gediz Nehri havzası boyunca karasal nitelikli Akdeniz iklimi hâkimken doğu ve dağlık 


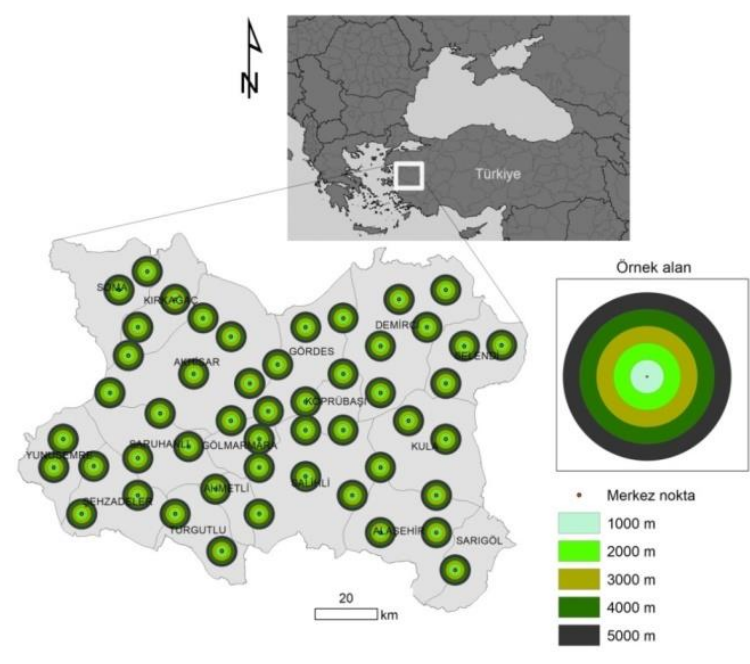

Şekil 1. Çalışma alanının birbirinden farklı mesafedeki örnek alanların coğrafi konumu

bölgelerde İç Anadolu Bölgesi'nin karasal ikliminin de etkileri görülür (Öztürk ve ark., 2017). Bitki örtüsü; makiler, ormanlar ve alpin bitkilerinden oluşmaktadır.

Türkiye İstatistik Kurumu 2019 yılı verilerine göre nüfusu 1.440.611 olan ilin \%82'si Gediz Havzası sınırındadır ve yüzölçümü 13.339 km²'dir. Ege bölgesinin önemli doğal göllerinden birisi olan Marmara Gölü il sınırları içerisindedir. Çalışma alanının batısında ve Gediz Nehri havzası boyunca karasal nitelikli Akdeniz iklimi hâkimken doğu ve dağlık bölgelerde İç Anadolu Bölgesi'nin karasal ikliminin de etkileri görülür (Öztürk ve ark., 2017). Bitki örtüsü; makiler, ormanlar ve alpin bitkilerinden oluşmaktadır.

Ormanlarda yaygın olarak kızılçam (Pinus brutia Ten.), karaçam (Pinus nigra Arnold), kestane (Castanea sativaMill.), boylu ardıç (Juniperus excelsa Bill.), sabin ardıcı (Juniperus sabina L.), mazı meşesi (Quercus infectoria Oliver) görülürken, dere içlerinde dişbudak (Fraxinus ornus L.), derici sumağı (Rhus coriaria L.), ova akçaağacı (Acer campestre L.) ve saçlı meşeye (Quercus cerris L.) rastlanmaktadır (Şık ve Gemici, 2009).

Çalışma kapsamında, coğrafi bilgi sistemleri ve uzaktan algılama yöntemlerinden yararlanılmıştır. Çalışma alanında rastgele dağılım gösteren 50 farklı nokta seçilerek, 5 farklı uzaklıkta (1000 m, 2000 m, 3000 m, 4000 m, 5000 m) örnek alanlar oluşturulmuştur. Örnek alanların dairesel olmasının sebebi, peyzaj metriklerinin hesaplanmasında olası kenar etkisinin minimize edilmesidir. Farklı uzaklıkların seçilmesinin nedeni, arazi çeşitliliği ve karbon depolama potansiyeli arasındaki ilişkinin varyasyonunu incelemektir. Çalışmanın materyalini; Copernicus Arazi Gözlem Hizmetlerinin (Copernicus Land Monitoring Service) web sitesinden ücretsiz olarak indirilen 2018 yılına ait 100 m çözünürlükteki CORINE Arazi Örtüsü (CLC; CORINE Land Cover) haritası ve Amerika Birleşik Devletleri Jeoloji Araştırmaları Kurumu'nun açık erişimli görüntülerinden 30 $\mathrm{m}$ çözünürlükteki Landsat 8 uydu görüntüsü oluşturmaktadır. Analizler, $\mathrm{R}$ istatistiksel yazılımı ve ArcMap10.7'de yapılmıştır.

İlk olarak, üçüncü düzeydeki CLC 2018 haritası tekrar sınıflandırılmıştır. Makro sınıfların birinci düzeye dönüştürülmesinde referans alınan kodlar Çizelge 1'de sunulmuştur.

Çizelge 1. CORINE (CLC) makro sınıflarının üçüncü düzeyden birinci düzeye göre tekrar sınıflandırılması

\begin{tabular}{lc}
\hline CLC makro sınıf kodu & CLC sınıfı (birinci düzey) \\
\hline $111,112,121,124,131,133,142$ & Yapay yüzey \\
$331,332,333,334$ & Çorak alan
\end{tabular}

211, 212, 221, 223, 231, 242, 243

Tarım alanı

$311,312,313$

Orman

$321,323,324$

Diğer bitki örtüsü

$411,422,512$

Su yüzeyi

CLC'nin yeniden sınıflandırılmasına paralel olarak, karasal karbon depolama potansiyelinin hesaplanması amacıyla vejetasyonun aktif olduğu dönemde indirilen Landsat 8 uydu görüntüsüne ait 4 . (kırmızı) ve 5 . (yakın kızıötesi) bantlar kullanılmıştır. Analizlerin yapılmasından önce, ilgili bantlar ArcMap10.7 yazılımında çalışma alanına sınırına göre kesilmiş ve bantlara ait yansıtma değerleri hesaplanmıştır. $\mathrm{Bu}$ işlemin tamamlanmasında, uydu görüntüsüne ait meta veri dosyası kullanılmıştır.

Normalize edilmiş bitki örtüsü farkı indeksi (NDVI), genellikle bir uzay platformundan alınan uzaktan algılama ölçümlerini analiz etmek için kullanılabilen ve gözlemlenen hedefin canlı yeşil bitki örtüsü içerip içermediğini değerlendiren basit bir grafik göstergedir. Negatif NDVI değerleri (-1'e yaklaşan değerler) suya karşılık gelir. Sıfıra yakın değerler (-0.1 ile 0.1) genellikle çorak kaya, kum veya kar alanlarını temsil etmektedir. Son olarak, düşük, pozitif değerler çalı ve otlakları (yaklaşık 0.2 ile 0.4 ) temsil ederken, yüksek değerler (1'e yaklaşan değerler) ılıman ve tropikal yağmur ormanlarını göstermektedir. NDVI formülü aşağıda yer almaktadır:

$$
N D V I=\frac{N I R-R e d}{N I R+R e d}(1)
$$

Formüle göre; NDVI normalize edilmiş bitki örtüsü farkı indeksini; NIR, yakın kızılötesi bantı; Red ise kırmızı bantı ifade etmektedir.

Uzaktan algılama yöntemleri kullanılarak, yer üstü biyokütle hesaplanmakta ve karasal karbon potansiyeli doğrudan belirlenebilmektedir. Bu kapsamda, arazi verilerinin uzaktan algılama verileri ile entegre edildiği araştırmalar da 
bulunmaktadır. Arazi verileri üzerinden farklı bitki türleri için alometrik modeller oluşturularak parametrik (regresyon analizleri) ve parametrik olmayan (örneğin $k$-en yakın komşu tekniği) istatistiksel yöntemlerden yararlanılmaktadır. Bu çalışmada, Myeong vd. (2006) tarafından önerilen ve NDVI tabanlı karbon depolama potansiyelinin tahmin edilmesini sağlayan formül kullanılmıştır:

$$
\text { Karbon }=\alpha \cdot e^{N D V I \cdot b}(2)
$$

Formülde $\alpha$ değeri 0.107 .2 , b değeri ise 0.0194 olarak alınmıştır. Bu değerler, Myeong vd. (2006) tarafından deneysel araştırmalar sonucu oluşturulmuştur. Formülün haritaya uygulanmasında raster hesaplama aracı kullanılmadan veri dönüşümü yapılmıştır. Veri kalibrasyonunun sağlanması bakımından $30 \mathrm{~m}$ çözünürlükteki veri, $100 \mathrm{~m}$ çözünürlükte olacak şekilde dönüştürülmüştür. Karbon depolama potansiyeli değeri, farklı büyüklükteki örnek alanlara bölgesel istatistik (zonal statistics) aracılığılla atanmıştır.

Bu çalışmada peyzaj çeşitliliğini belirlemek amacıyla peyzaj düzeyinde hesaplanan Shannon çeşitlilik indeksi (SHDI), yama yoğunluğu (PRD) ve Simpson eşitlik indeksi (SIEI) kullanılmıştır. SHDI, bir topluluktaki tür çeşitliliğini karakterize eder. Indeks, mevcut türlerin hem bolluğunu hem de eşitliğini açıklar. Toplam tür sayısına $\left(p_{i}\right)$ göre tür $\mathrm{i}$ oranı hesaplanır ve daha sonra bu oranın $\left(\ln p_{i}\right)$ doğal logaritması ile çarpılır. Ortaya çıkan ürün türler arasında toplanır ve -1 ile çarpılır. SHDI formülü aşağıda sunulmuştur:

$$
\operatorname{SHDI}(x)=-\sum_{j=i}^{S} p_{i} \ln p_{i}(3)
$$

PRD, peyzaj sınırı içinde bulunan farklı yama türlerinin sayısının ( $m$ ) toplam peyzaj alanına (A) bölünmesiyle elde edilen sayıya eşittir. Çarpım işlemi mevcut birimi $\left(\mathrm{m}^{2}\right)$, hektara dönüştürmek için yapılır. PRD formülü aşağıda yer almaktadır:

$$
P R D=\frac{\mathrm{m}}{\mathrm{A}}(10,000)(100)(4)
$$
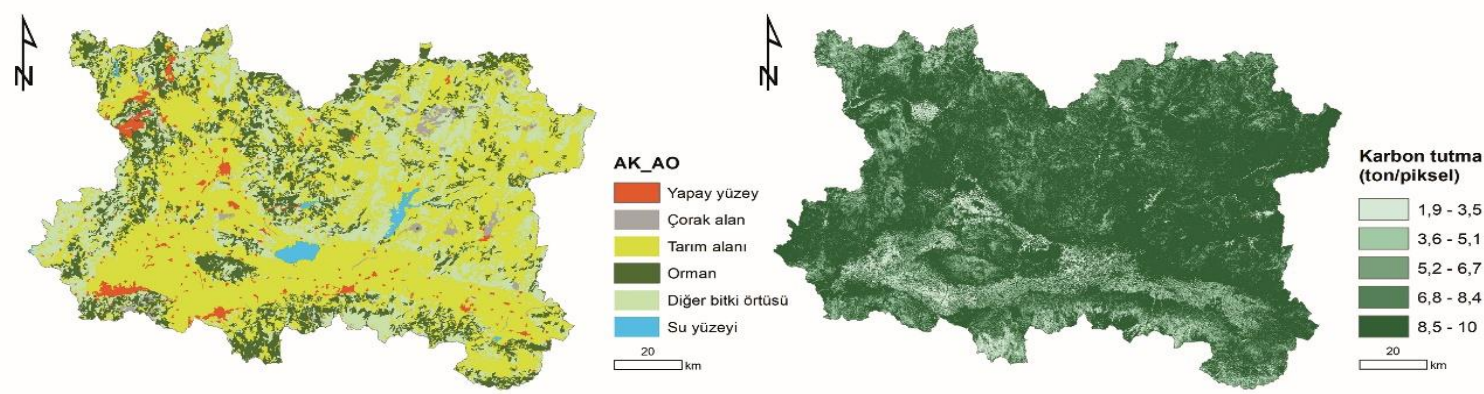

Metrikler her bir örnek alan için R istatistiksel yazılımında hesaplanmıştır. Metrik hesaplarının yapılabilmesi amacıyla açık erişim sağlanan landscapemetrics $R$ paketi kullanılmıştır (Hesselbarthve ark., 2019). Çeşitlilik değerleri ile yer üstü karbon tutumu değerlerinin, korelasyon analizi ile değerlendirilmesinde corrplot $\mathrm{R}$ paketinden yararlanılmıştır.

\section{BULGULAR VE TARTIŞMA}

CORINE 2018 yılı verisinden üretilen 100 m çözünürlükteki arazi kullanımı/arazi örtüsü ve uydu görüntüsü üzerinden karbon indeksinin hesaplanmasıyla üretilen karbon tutma haritaları Şekil 2'de sunulmuştur. AK/AO haritasına göre Manisa'nın \%2.42'si yapay yüzeylerden, \%1.56'sı çorak alanlardan, \%53.02'si tarım alanlarından, \%16.52'si ormanlardan, \%25.44'ü diğer bitki örtüsünden, \%1.04'ü ise su yüzeylerinden oluşmaktadır. Karbon tutma değerleri, 1 ile 10 arasında yeniden ölçeklendirilmiştir ve 5 grupta sınıflandırıımıştır. Bunlar sırasıyla; çok düşük (1.9-3.5); düşük (3.6-5.1); orta (5.2-6.7); yüksek (6.8-8.4) ve çok yüksektir (8.5-10). Karbon depolama potansiyeli bakımından çok düşük olan alanlar alanın \%3.66'sını, düşük alanlar alanın \%9.60'ını, orta alanlar alanın \%12.05'ini, yüksek alanlar alanın \%10.49'unu, çok yüksek alanlar ise alanın \%64.20'sini oluşturmaktadır.

Korelasyon analizi sonuçları incelendiğinde, Shannon çeşitlilik indeksi (SHDI) ve karbon tutma değişkenleri arasındaki korelasyon katsayısı 1000 m'de $0.40 ; 2000$ m'de $0.47 ; 3000 \mathrm{~m}^{\prime}$ de $0.48 ; 4000 \mathrm{~m}^{\prime}$ de $0.41 ; 5000 \mathrm{~m}^{\prime}$ de ise $0.18^{\prime}$ dir. Korelasyon grafiklerinde, önemsiz ilişkiler çarpı $(X)$ işareti ile gösterilmiştir (Şekil 3).

Şekil 2. 2018 yılına ait Manisa AK/AO ve karbon tutma haritaları (AK/AO: Arazi Kullanımı/Arazi Örtüsü) 

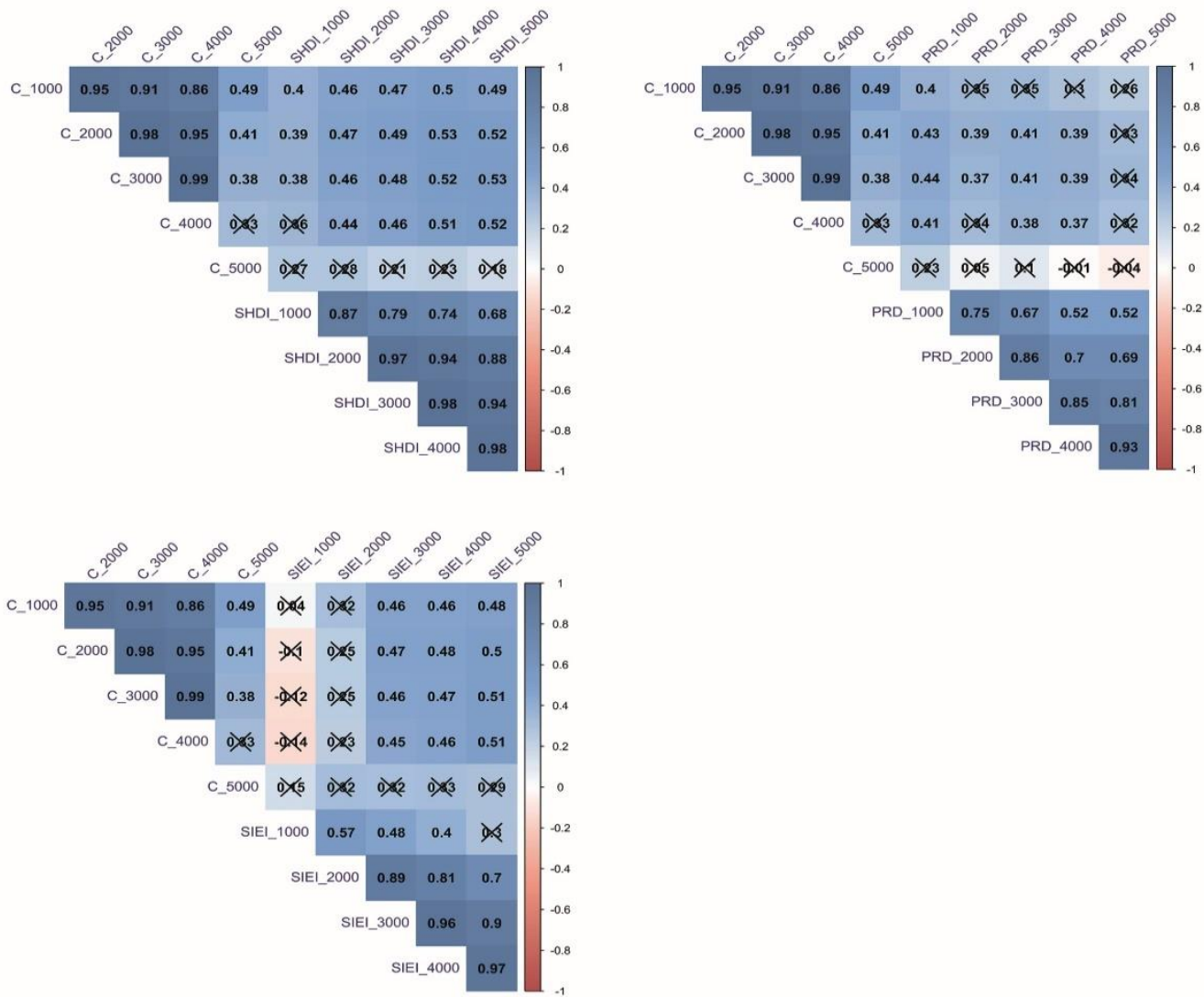

Şekil 3. Peyzaj çeşitliliği ve karbon depolama potansiyeli arasındaki korelasyon analizi grafikleri (SHDI: Shannon çeşitlilik indeksi, PRD: yama yoğunluğu, SIEI: Simpson çeşitlilik indeksi, C: karbon depolama potansiyeli)

Yama yoğunluğu (PRD) ve karbon depolama potansiyeli arasındaki ilişki incelendiğinde ilişkinin $(5000 \mathrm{~m}$ mesafe dışındaki) pozitif yönlü olduğu görülmektedir. Korelasyon katsayısı 1000 m'de 0.40; 2000 m'de 0.39; 3000 m'de 0.41; $4000 \mathrm{~m}$ 'de $0.37 ; 5000 \mathrm{~m}$ 'de ise -0.04 'dir. Simpson çeşitlilik indeksi (SIEI) ve karbon depolama potansiyeli arasındaki ilişki incelendiğinde ilişkinin diğer bağımsız değiş̧enlerde olduğu gibi pozitif olduğu dikkat çekmektedir. Korelasyon katsayısı 1000 m'de 0.04; 2000 m'de $0.25 ; 3000$ ve 4000 $\mathrm{m}^{\prime}$ de $0.46 ; 5000 \mathrm{~m}^{\prime}$ de ise $0.29^{\prime}$ dur. Sonuç olarak, bütün peyzaj çeşitlilik metrikleri peyzaj çeşitliliği ve karbon depolama potansiyeli arasındaki ilişkiyi $3000 \mathrm{~m}$ 'de en iyi düzeyde açıklamıştır. SHDI'nın bu ilişkiyi diğer metriklere göre daha iyi açıkladığı görülmektedir. Illişkinin düzeyi ortadır ve yönü pozitiftir.

Güncel çalışmalar, çeşitli arazi örtüsü haritalama tekniklerinin karbon depolama potansiyeli üzerinde etkili olduğunu belirtmiştir. Örneğin; Sumarga et al. (2020) Batı Java, Endonezya'da tropikal ekosistemde yürüttüğü araştırmasında bazı jeoistatistiksel enterpolasyon tekniklerinin kullanıldığı arazi örtüsü haritaları üzerinden tabakalaşmaya (stratification) gerek olmaksızın karbon depolama potansiyelini belirlemede güçlü araçlar olduğunu ifade etmiştir. Ancak bu çalışmada, arazi örtüsünün yanı sıra rakım değişkeninden de yararlanılmıştır.

Li et al. (2015), kuzeydoğu Çin'de ılıman bir ormandaki yer üstü biyokütleyi haritalamak için LiDAR (Light Detection and Ranging) SPOT-6 verilerini entegre etmiş, jeoistatistiksel modelleme uygulamış ve regresyon kriging tekniğinin karbon depolama potansiyelini belirlemede başarılı olduğunu belirtmiştir. Bu çalışma, bu tekniğin, kabaca benzer koşullara sahip daha geniş bölgelerde, yani gelişmekte olan ülkelerde 500 hektardan daha az alanlara sahip tropikal ormanlarda, özellikle benzer arazi örtüsü kompozisyonuna sahip korunan orman olarak yönetilen alanlarda, yer üstü karbon haritalaması için uygulanmasını önermektedir. Bu çalışmaların ortaya attı̆̆ı tartışma, karbon depolama potansiyelini belirlemede arazi örtüsünün tek başına bir değişken olarak kullanılmasının yanı sıra farklı değişkenlere (yükseklik, bakı vb.) ihtiyaç duyulduğunun bir göstergesidir. Bu makalede sunulan çalışma, her ne kadar SHDI indeksi ile orta düzeyde önemli korelasyon bulmuş olsa da, AK/AO'nun yanı sıra önceki çalışmalara dayalı olarak bundan sonraki çalışmalarda karbon depolama potansiyelini belirlemek amacıyla çeşitli değişkenlerin kullanılması önerilmiştir. Ayrıca, yüksek veri kalitesine sahip 
LiDAR nokta bulutu vb. uzaktan algılama tekniklerinin kullanılması da tahmin modelinin başarısını etkilemektedir. Dolayısıyla, sunulan çalışmada CORINE yerine, çözünürlüğü daha yüksek veriye dayanan arazi örtüsü haritası korelasyon analizinde tamamen farklı sonuçlar verebilir. Bu bağlamda, karbon haritalaması için eğim, bakı ve bitki örtüsü indekslerine (ücretsiz DEM ve uydu görüntülerinden üretilebilecek çevresel indeksler) dayanan düşük maliyetli ve pratik yöntemlerin geliştirilmesine ihtiyaç vardır. Arazi verilerine dayanan değişkenleri (özellikle toprak ve jeoloji gibi bitki büyümesi için kritik olanlar) uzaktan algılama modellerine dâhil etmek, doğruluk değerlendirmesi için potansiyel bir seçenek olacaktır. Bu değişkenlerin regresyon modellemesinde ve yer üstü karbon haritalamasında kullanılmasına izin vermek için değişkenlerin uzamsal verilerinin erişilebilir olması gerekmektedir.

Arazi örtüsü verisi üzerinden karbon depolama potansiyelini tahmin etmek, özellikle orman yönetimini destekleyebilir ve yangın riski yönetimi de dâhil olmak üzere mekânsal planlama için girdi sağlayabilir. Bir yer üstü karbon haritasının üretilmiş olması, yangın potansiyeli bilgisi ile birleştirildiğinde, orman yangınlarından kaynaklanan yer üstü karbon kaybını tahmin etmek ve ayrıca yangın önleme için yüksek öncelikli alanları belirlemek için yararlı olabilir. Daha genel bir uygulamada, birçok çalışma, farklı arazi kullanım yönetimi seviyelerinde arazi kullanım planlamasının desteklenmesinde karbon tutma ve depolama dâhil olmak üzere, birden çok ekosistem hizmeti hakkında uzamsal bilginin kullanımını başarıyla göstermiştir (Wu ve ark., 2018).

\section{SONUÇ}

Bu çalışma kapsamında, Manisa Il'inde peyzaj çeşitliliği ve karbon depolama potansiyeli arasındaki ilişkinin incelenmesi için bir dizi analiz yapılmıştır. Bu kapsamda, Manisa'da karbon depolama potansiyeli ve peyzaj çeşitliliği düzeyi peyzaj bütününde değişiklik gösterdiği gözlemlenmiştir. Bu değişikliğin nedeni, arazi örtüsünün heterojen yapıda olmasından kaynaklanmaktadır. Manisa gibi özellikle doğal alanların homojen olarak yayılış göstermediği illerde, arazi örtüsü verileri ile karbon tutma seviyesinin ilişkilendirilmesi özellikle doğa koruma temelli peyzaj planlama çalışmalarında girdi verisi olarak kullanılabilir. Bu çalışmanın sonuçları, uydu görüntüleri ve yardımcı veriler yardımıyla, il ölçeğinde karbon depolama potansiyelinin kısmen tahmin edilebileceğini göstermektedir. Yapılan korelasyon analizlerine göre, peyzaj çeşitliliği ile karbon depolama potansiyeli arasında orta düzeyde önemli $(p<0.05)$ ve pozitif ilişkiler bulunmuştur. Bundan sonraki çalışmalarda, AK/AO verisini kullanılarak karbon depolama potansiyelinin hızlı ve pratik ölçülmesini sağlayacak yeni metrikler üretilebilir. Böylece, $A K / A O$ değişimlerine bağı olarak arazideki karbon tutma değişimi de izlenebilir. Sonuç olarak, bu çalışmanın çıktıları, çevresel izleme çalışmalarına entegre edilebilir ve AK/AO verileri daha kapsamlı peyzaj değerlendirmeleri için kullanılabilir.

\section{KAYNAKLAR}

Botequilha Leitão A, Ahern J (2002) Applying landscape ecological concepts and metrics in sustainable landscape planning. Landscape and Urban Planning59(2): 65-93.

Brunori E, Salvati L, Mancinelli R, Smiraglia D, Biasi R (2017) Multi-temporal land use and cover changing analysis: The environmental impact in Mediterranean area. International Journal of Sustainable Development ve World Ecology24(3) 276-288.

Cardinale BJ, Gross K, Fritschie K, Flombaum P, Fox JW, Rixen C, Ruijven J, van Reich PB, Scherer-Lorenzen M, Wilsey BJ (2013) Biodiversity simultaneously enhances the production and stability of community biomass, but the effects are independent. Ecology94(8): 1697-1707.

Chave J, Andalo C, Brown S, Cairns MA, Chambers JQ, Eamus D, Fölster $H$, Fromard $F$, Higuchi $N$, Kira $T$, Lescure JP, Nelson BW, Ogawa $H$, Puig $H$, Riéra B, Yamakura, T (2005) Tree allometry and improved estimation of carbon stocks and balance in tropical forests. Oecologia145(1): 87-99.

Chen Y, Lu H, Li J, Xia J (2020) Effects of land use cover change on carbon emissions and ecosystem services in Chengyu urban agglomeration, China. Stochastic Environmental Research and Risk Assessment34(8): 1197-1215.

Chowdhury M, Hasan ME, Abdullah-Al-Mamun MM (2020) Land use/land cover change assessment of Halda watershed using remote sensing and GIS. The Egyptian Journal of Remote Sensing and Space Science23(1): 63-75.

Cushman SA, McGarigal K, Neel MC (2008) Parsimony in landscape metrics: Strength, universality, and consistency. Ecological Indicators8(5): 691-703.

Davies ZG, Edmondson JL, Heinemeyer A, Leake JR, Gaston KJ (2011) Mapping an urban ecosystem service: Quantifying above-ground carbon storage at a citywide scale. Journal of Applied Ecology48(5): 11251134.

Dewan AM, Yamaguchi Y (2009) Land use and land cover change in Greater Dhaka, Bangladesh: Using remote sensing to promote sustainable urbanization. Applied Geography29(3): 390-401.

Frank S, Fürst C, Koschke L, Makeschin F (2012) A contribution towards a transfer of the ecosystem service concept to landscape planning using landscape metrics. Ecological Indicators21:30-38.

Golkar F, Shirvani A (2020) Spatial and temporal distribution and seasonal prediction of satellite measurement of CO2 concentration over Iran. International Journal of Remote Sensing41(23): 8891-8909.

Harpole WS, Sullivan LL, Lind EM, Firn J, Adler PB, Borer ET, Chase J, Fay PA, Hautier $Y$, Hillebrand $H$, MacDougall AS, Seabloom EW, Williams R, Bakker JD, Cadotte 
MW, Chaneton EJ, Chu C, Cleland EE, D'Antonio C, Wragg PD (2016) Addition of multiple limiting resources reduces grassland diversity. Nature:537(7618): 93-96.

Hesselbarth MH, Sciaini M, With KA, Wiegand K, Nowosad J (2019) landscapemetrics: an open-source $R$ tool to calculate landscape metrics. Ecography 42(10): 16481657.

Hooper DU, Adair EC, Cardinale BJ, Byrnes JEK, Hungate BA, Matulich KL, Gonzalez A, Duffy JE, Gamfeldt L, O'Connor MI (2012) A global synthesis reveals biodiversity loss as a major driver of ecosystem change. Nature486(7401): 105-108.

Houghton RA, Nassikas AA (2017) Global and regional fluxes of carbon from land use and land cover change 18502015. Global Biogeochemical Cycles31(3): 456-472.

Hu Y, BatunacunZhen L, Zhuang D (2019) Assessment of Land-Use and Land-Cover Change in Guangxi, China. Scientific Reports9(1):2189.

Jantz P, Goetz S, Laporte N (2014) Carbon stock corridors to mitigate climate change and promote biodiversity in the tropics. Nature Climate Change4(2): 138-142.

Lausch A, Herzog F (2002) Applicability of landscape metrics for the monitoring of landscape change: Issues of scale, resolution and interpretability. Ecological Indicators2(1): 3-15.

Lausch Angela, Blaschke T, Haase D, Herzog F, Syrbe RU, Tischendorf L, Walz U (2015) Understanding and quantifying landscape structure - A review on relevant process characteristics, data models and landscape metrics. Ecological Modelling295: 31-41.

Li H, Wu J (2004) Use and misuse of landscape indices. Landscape Ecology19(4): 389-399.

Li W, Niu Z, Liang X, Li Z, Huang N, Gao S, Wang C, Muhammad S (2015) Geostatistical modeling using LiDAR-derived prior knowledge with SPOT-6 data to estimate temperate forest canopy cover and aboveground biomass via stratified random sampling. International Journal of Applied Earth Observation and Geoinformation41: 88-98.

Liu S, Li X, Chen D, Duan Y, Ji H, Zhang L, Chai Q, Hu X (2020) Understanding Land use/Land cover dynamics and impacts of human activities in the Mekong Delta over the last 40 years. Global Ecology and Conservation22: e00991.

McGarigal K (2014) Landscape Pattern Metrics. In Wiley StatsRef: Statistics Reference Online. American Cancer Society.

Muñoz-Rojas $M$, Jordán A, Zavala LM, Rosa DD, AbdElmabod SK, Anaya-Romero, M (2015) Impact of Land Use and Land Cover Changes on Organic Carbon Stocks in Mediterranean Soils (1956-2007). Land Degradation ve Development26(2): 168-179.

Myeong S, Nowak DJ, Duggin MJ (2006) A temporal analysis of urban forest carbon storage using remote sensing. Remote Sensing of Environment101(2): 277-282.

Ni-Meister W, Lee S, Strahler AH, Woodcock CE, Schaaf C, Yao T, Ranson KJ, Sun G, Blair JB (2010) Assessing general relationships between aboveground biomass
GÜLçiN D

and vegetation structure parameters for improved carbon estimate from lidar remote sensing. Journal of Geophysical Research: Biogeosciences115(G2).

Öztürk MZ, Çetinkaya G, Aydin S (2017) Köppen-Geiger İklim Sınıflandırmasına Göre Türkiye'nin Iklim Tipleri. Coğrafya Dergisi35: 17-27.

Patenaude G, Hill RA, Milne R, Gaveau DLA, Briggs BBJ, Dawson TP (2004) Quantifying forest above ground carbon content using LiDAR remote sensing. Remote Sensing of Environment93(3): 368-380.

Perre FV, Willig MR, Presley SJ, Andemwana FB, Beeckman $H$, Boeckx $P$, Cooleman $S$, Haan $M$, Kesel AD, Dessein $S$, Grootaert P, Huygens D, Janssens SB, Kearsley E, Kabeya PM, Leponce M, Broeck DV, Verbeeck H, Würsten B, Verheyen E (2018) Reconciling biodiversity and carbon stock conservation in an Afrotropical forest landscape. Science Advances4(3): eaar6603.

Poulter B, Frank D, Ciais P, Myneni RB, Andela N, Bi J, Broquet G, Canadell JG, Chevallier F, Liu YY, Running SW, Sitch S, van der Werf GR (2014) Contribution of semi-arid ecosystems to interannual variability of the global carbon cycle. Nature509(7502): 600-603.

Sabatini FM, Andrade RB, Paillet Y, Ódor P, Bouget C, Campagnaro T, Gosselin F, Janssen P, Mattioli W, Nascimbene J, Sitzia T, Kuemmerle T, Burrascano S (2019) Trade-offs between carbon stocks and biodiversity in European temperate forests. Global Change Biology25(2): 536-548.

Sande MT, Poorter L, Kooistra L, Balvanera P, Thonicke K, Thompson J, Arets EJM M, Alaniz NG, Jones L, Mora F, Mwampamba TH, Parr T, Peña-Claros M (2017) Biodiversity in species, traits, and structure determines carbon stocks and uptake in tropical forests. Biotropica49(5): 593-603.

Singh H, Garg RD, Karnatak HC, Roy A (2018) Spatial landscape model to characterize biological diversity using R statistical computing environment. Journal of Environmental Management206: 1211-1223.

Sütünç HS, Çorbacı, ÖL (2020) Building Urban Green Infrastructure Systems Using Ecological Planning Principles: Siirt Sample. Düzce Üniversitesi Orman Fakültesi Ormancılık Dergisi16(2): 70-88.

Şık L, Gemici Y (2009)Yunt Dağı (Manisa) Orman Vejetasyonunun Bitki Sosyolojisi Yönünden Araştırılması.Celal Bayar Üniversitesi Fen Bilimleri Dergisi5(1): 75-86.

Sintayehu DW, Belayneh A, Dechassa N (2020) Aboveground carbon stock is related to land cover and woody species diversity in tropical ecosystems of Eastern Ethiopia. Ecological Processes9(1): 37.

Strassburg BBN, Kelly A, Balmford A, Davies RG, Gibbs HK, Lovett A, Miles L, Orme CDL, Price J, Turner RK, Rodrigues ASL (2010) Global congruence of carbon storage and biodiversity in terrestrial ecosystems. Conservation Letters3(2): 98-105.

Sumarga E, Nurudin N, Suwandhi I (2020) Land-Cover and Elevation-Based Mapping of Aboveground Carbon in a 
Tropical Mixed-Shrub Forest Area in West Java, Indonesia. Forests11(6): 636.

Uuemaa E, Antrop M, Roosaare J, Marja R, Mander Ü (2009) Landscape metrics and indices: An overview of their use in landscape research. Living reviews in landscape research3(1): 1-28.

Verburg PH, Alexander P, Evans T, Magliocca NR, Malek Z, Rounsevell MD, van Vliet J (2019) Beyond land cover change: Towards a new generation of land use models. Current Opinion in Environmental Sustainability38: 77-85.

Wu X, Wang S, Fu B, Liu Y, Zhu Y (2018) Land use optimization based on ecosystem service assessment:
A case study in the Yanhe watershed. Land Use Policy72: 303-312.

Yu Z, Lu C, Tian H, Canadell JG (2019) Largely underestimated carbon emission from land use and land cover change in the conterminous United States. Global Change Biology25(11): 3741-3752.

Yuan Z, Wang S, Ali A, Gazol A, Ruiz-Benito P, Wang X, Lin F, Ye J, Hao Z, Loreau M (2018) Aboveground carbon storage is driven by functional trait composition and stand structural attributes rather than biodiversity in temperate mixed forests recovering from disturbances. Annals of Forest Science 75(3): 67. 